resistant; the chemical features controlling such factors were illustrated. Practical studies were again included; for example, the effect on the wet abrasion resistance of emulsion paint films of using volatile coalescent agents to replace partially the plasticizer. Detailed studies of the structure and analysis of alkyd resins, carried out over the past few years, were comprehensively surveyed. Media incorporating drying oils suffer from a tendency to yellow; some of the factors influencing this tendency, such as the catalytic action of organic bases and the chemical reactions involved, have been uncovered.

As might be expected from the wide range of materials used in paint manufacture, the work of the analytical laboratory has to cover an extremely wide field. Work on display included analytical schemes for white pigments and protective colloids, the application (sometimes in modified form) of standard techniques, for example, chromatography, to problems of paint analysis and the special micro techniques developed to study paint blemishes and defects.

The growing interest in microbiological studies on paint has been reflected, as already described, in the provision of a special laboratory in the Jordan Laboratory. The display concerned identification of the various moulds, fungi or algae responsible for defects and assessments of the protective action of various chemicals against such microbiological attack. Special features appertaining to exposure under tropical conditions were also shown.

It is impossible in an article of this length even to list all the exhibits; the above will have indicated, however, the fascinating problems involved in paint manufacture and application, and the progress made at one research centre dedicated to their study.

L. VALENTINE

\title{
SELECTION AND TRAINING OF COMPUTER PROGRAMMERS
}

\begin{abstract}
A SESSION of Sub-section A* (Mathematics) of the British Association at the recent Cardiff meeting was devoted to consideration of the selection and training of computer programmers. It took the form of an introduction followed by three short lectures and a very brief general discussion.

Introducing the subject, Dr. J. Howlett (Atomic Energy Research Establishment, Harwell) said that the electronic computer, although almost a household word, is really very new. Its rate of development has been remarkable, and it has put into our hands great and rapidly increasing logical and arithmetical powers ; the use of computers is spreading widely in all fields, scientific and otherwise, but it is unlikely that their powers are yet fully appreciated or that the real nature of the task of programming them is completely understood. It is, therefore, only to be expected that there are sharp differences of opinion about the use and organization of computers and the types of person to be employed in connexion with them, how to select these people and how to train them.
\end{abstract}

When setting up a Computing Group, two important questions have to be settled : the relations with the establishment it serves, and the amount of stratification of the work within the Group. The first means deciding towards which of two extremes the Group shall tend : towards 'closed shop' working in which only the members of the Computer Group write programmes, or towards 'open shop' when anyone who wishes to do so may write his own programmes. The second concerns the extent to which the different kinds of tasks involved in going from the problem expressed in, say, the language of physics to a computer programme shall be performed by different people; these steps are formal mathematical analysis, numerical analysis, planning the flow or general structure of the programme and, finally, the detailed coding. The different tasks make quite different demands, and so if there is to be much division of labour, staff of several different types will be needed. Dr. Howlett suggested that scientific establishments tend to favour 'open shop' working and little stratification, while the reverse applies to commercial organizations and computer units tied to large engineering enterprises; and that the latter are more inclined than the former to use selection methods based on formal aptitude and psychological tests. Finally, he referred to the recent developments in. efficient automatic programming systems which make it reasonably easy for the non-specialist to write the programmes to do his own work; in many computer units this has resulted in much work being put on to the machine by people who could not be called programmers at all. This possibility has been brought about by the production of more powerful machines in the past few years and is certain to continue as computer power and the appreciation of this increases.

Mr. J. J. Foody (Short Bros. and Harland, Ltd., Belfast) described the experience and practice in his own Company, the field of which is aircraft engineering. Its computer unit in Belfast uses an English Electric Deuce. The staff is grouped into three classes : systems analysts, programmers and operators. The first are honours graduates who do all the essential mathematical work on the problems, taking the development to the stage where it can be used directly as the basis of a computer programme. 'Those in the second group are generally of pass-degree standing; they take over the work of the analysts and turn it into a programme, doing all the work of flow-charting, coding and testing. The operators (for card punching and machine running) need have no academic qualifications; Mr. Foody said they had at one time tried to use pass-degree people as operators, but the results were unsatisfactory. This led the Company to adopt the principle of looking for the lowest grade of staff capable of doing any particular type of work-over-qualified people become dissatisfied and look for a change. Programmers should have the ability both to see the essentials of a problem and to attack it in a logical and orderly manner ; the Company therefore uses in its selection process problems intended to test these qualities, as for example variations on the classical coin-weighing problem, questions on the connexions for a simple circuit or the analysis of some familiar numerical process such as the digit-by-digit method for extracting a square root. Experience in recruiting young people has suggested that failure to grasp fundamentals is often 
a fault of the teaching rather than of the person. Mr. Foody commented that the search for suitable staff had been made difficult by the shortage of mathematicians, particularly numerical analysts, in Northern Ireland.

For training, new recruits are given first an introduction to the kind of work done in the computing group, which covers a very wide range; this is followed by instruction in the simpler techniques of programming, and they are then left for about two weeks to study the programme manual, working out examples so far as possible on their own. After this they are taught more about the logical structure of programmes, with particular emphasis on the ideas of loops and sub-routines and from then onwards take up progressively more difficult 'live' work. A lot of emphasis is put on the need to keep proper records of all work done and the importance of neat and orderly paper-work. Mr. Foody concluded by saying that he considers the quality of management to be of vital importance in a computing group. Good management will not only ensure that the group is well organized and run, but also that the power and value of high-speed computation are made clear to all those who might benefit.

Mr. P. V. Ellis (International Computers and Tabulators, Ltd.) described the method of selection and training used in his Company, which makes computing, data processing and accounting machinery on a large scale. Programming to them means a wide range of activities, including service to customers to help with the use of existing machines, provision of assembly, interpretative and related programmes, detailed appraisal of projected machines in advance of any construction and assistance in the logical design of new machines.

Primary selection is made by interview and formal aptitude tests. A candidate successful at this stage embarks on a training course, but may at any stage of this be declared unsuccessful if it has become clear that he is not going to reach the required standard. The tests, the form of which has been evolved over several years, are administered by a professional organization; they do not call on factual knowledge, but are intended to test observational powers and ability to think quickly and logically. They include problems in arithmetic, in the detection of faults in statements, in the application of selection rules, in logical inference and in logical deduction from sets of statements. Existing staff are used as a control, and $\mathrm{Mr}$. Ellis said that the distribution of scores is satisfactorily stable. Candidates are assessed objectively by these tests and subjectively by personal interviews held before the results of the tests are known; agreement is usually good, and if there is any disagreement it is the usual practice to reject the candidate.

Training starts with a residential course lasting five weeks, new people being taken on in groups so that a class of ten or so can be formed. There are lectures, written papers and various co-operative activities. Those who complete the course satisfactorily move into different groups in the Company and continue training on 'live' work, each with an experienced member of the staff as mentor until they can stand on their own feet. The Company considers that the contacts made during the training course are of very great value in helping new people to acclimatize themselves to their new environment and to gain confidence.

Mr. H. Devonald (Ferranti, Ltd.) said that the comments he had heard during the interval suggested to him that many in the audience were unfamiliar with the ideas of programming and that he proposed, therefore, instead of further accounts of selection and training methods, to explain the essential points by means of a simple example. He then showed how one constructed a programme to solve a general quadratic equation, reading the coefficients from tape and printing the roots; he used the notation of the Pegasus auto-code.

In the brief discussion which closed the meeting, the principal speaker was Dr. A. D. Booth (Birkbeck College, University of London), who emphasized the importance of a constant mathematical awareness in all computing work. He instanced the difficulties one can get into by attempting to solve a partial differential equation by finite-difference methods without having a proper understanding of the mathematies of the process.
J. HowletT

\section{PHYSICAL CHEMISTRY OF AEROSOLS}

\begin{abstract}
IRBORNE clouds of small particles, or aerosols,
A are so widespread in Nature and arise in so many phases of modern industry that their study brings together a large group of physicists, chemists, meteorologists and engineers, each, of course, with his own special interests but all concerned with the generation, dispersion, sampling, counting, sizing, structure, composition, growth and aggregation of small particles. Such a heterogeneous ensemble aggregited in Bristol during September 13-15 to sample twenty-four well-dispersed papers at a diseussion arranged by the Faraday Society, under the chairmanship of its president, Sir Harry Melville.

Broadly, there were four main topies for discussion : the nucleation of liquid and solid particles from the vapour phase ; the coalescence, growth, evaporation and stabilization of liquid droplets; chemical reactions involving aerosols; and light-scattering by aerosols.
\end{abstract}

After some introductory remarks by Dr. $R$. Lessing, the symposium opened with a review by Dr. J. W. Dunning (University of Bristol) of the Volmer Becker-Döring theory of homogeneous condensation and of various experimental studies of the phenomenon. Dr. Dunning was of the opinion that the results of expansion-chamber experiments had provided acceptable confirmation of the theory, but that condensation in expanding jets provided a more convenient and reliable technique of investigation.

Dr. B. J. Mason (Imperial College of Science and Technology, London) described some recent studies of homogeneous and heterogeneous nucleation of water aerosols involving vapour-liquid, supercooled liquid-solid and vapour-solid transitions. He underlined the limitations of the Volmer theory of homogeneous condensation and did not consider that this had been adequately tested and confirmed by experiment. He next discussed the growth of water droplets 